\title{
PERFILES DE SUSCEPTIBILIDAD ANTIMICROBIANA EN BACTERIAS AISLADAS EN CULTIVOS AGRÍCOLAS DE LA CUENCA DEL RÍO CHAMBO.
}

\section{Antimicrobial susceptibility profiles of bacteria isolated from agricultural crops in the Chambo river basin.}

Ana Carolina González-Romero* (iD), María Guadalupe Guamán-Chabla iD, María del Carmen Cordovez-Martínez (iD, Eliana Elizabeth Martínez -Duran (iD).

Universidad Nacional del Chimborazo, Facultad de Ciencias de la Salud, Carrera Laboratorio Clínico, Riobamba, Ecuador.

*ana.gonzalez@unach.edu.ec

$\mathrm{R}$ esumen

Introducción. Las enfermedades transmitidas por alimentos han aumentado en los últimos años, derivado del consumo de productos agrícolas contaminados con bacterias resistentes a antibióticos. Objetivo. Identificar los perfiles de resistencia antimicrobiana de bacterias aisladas en cultivos agrícolas de la cuenca del río Chambo.

Materiales y métodos. Se analizaron un total de 12 muestras de vegetales y hortalizas recolectadas de zonas agrícolas de seis puntos geográficos cercanos al río Chambo. El aislamiento e identificación de las bacterias se realizó por medio de pruebas convencionales empleando medios de cultivo conjuntamente con pruebas bioquímicas. El perfil de resistencia a los antibióticos se determinó por el método de difusión del disco en agar.

Resultados. Se identificaron (12/14) $85,7 \%$ bacterias pertenecientes a la familia Enterobacteriacea entre ellas: Citrobacter freundii, Citrobacter amalonaticus, Enterobacter cloacae, Proteus vulgaris, Klebsiella oxytoca y (2/14) 14,3\% correspondiente a Enterococcus faecalis. El 50\% de las enterobacterias presentaron resistencia a cefalosporinas de 3ra generación (ceftriaxona y ceftazidima), 50\% a kanamicina y $25 \%$ a imipenem, gentamicina y trimetoprim sulfametoxazol.

Conclusiones. Existe contaminación de los cultivos agrícolas vertidos con agua de regadío de la cuenca del río Chambo por especies de enterobacterias y E. faecalis; con altos porcentajes de resistencia a antibióticos de uso clínicos.

Palabras claves: Río Chambo, productos agrícolas, bacterias, resistencia, antibióticos.

\section{A bstract}

Introduction. Introduction. Foodborne illnesses have increased in recent years, derived from the consumption of agricultural products contaminated with pathogenic bacteria resistant to antibiotics. Objective. To identify the antimicrobial resistance profiles of pathogenic bacteria isolated in agricultural crops from the Chambo river basin.

Materials and methods. A total of 12 samples of vegetables and vegetables collected from agricultural areas of six geographical points near the Chambo River were analyzed. The isolation and identification of the bacteria was carried out by means of conventional tests culture media, together with biochemical tests. The antibiotic resistance profile was determined by the agar disk diffusion method.

Results. (12/14) 85.7\% human pathogenic bacteria belonging to the Enterobacteriacea family were identified, including: Citrobacter freundii, Citrobacter amalonaticus, Enterobacter cloacae, Proteus vulgaris, Klebsiella oxytoca and (2/14) 14.3\% corresponding to Enterococcus faecalis. $50 \%$ of the Enterobacteriaceae were resistant to 3rd generation cephalosporins (ceftriaxone and cftazidime), 50\% to kanamycin and $25 \%$ to imipenem, gentamicin and trimethoprim sulfamethoxazole.

Conclusions. The results obtained indicate a high contamination of agricultural crops dumped with 
irrigation water from the Chambo river basin by species of Enterobacteriaceae and E. faecalis; with high percentages of resistance to antibiotics for clinical use.

Keywords: Chambo River, agricultural products, bacteria, resistance, antibiotic.

Fecha de recepción: 13-10-2021 Fecha de aceptación: 30-11-2021 Fecha de publicación: 31-01-2021

\section{INTRODUCCIÓN}

El consumo de hortalizas verduras es vital para la salud humana puesto que poseen innumerables propiedades alimenticias, son fuente inagotable de vitaminas, minerales, fibra y energía; y pueden contribuir de alguna forma con la prevención de enfermedades cardiovasculares y gastrointestinales (1). Sin embargo, por sus características físicas y de cultivo, estos productos están expuestos a contaminación de tipo biológica y química, constituyendo un riesgo para la adquisición de enfermedades transmitidas por alimentos (ETA) (2).

La contaminación de los productos hortofrutícolas ocurre a partir de diversas fuentes como: uso de agua de riego contaminada, el suelo de cultivo, la materia fecal humana o animal, el aire, el equipo de cultivo y manejo, los recipientes y utensilios, los materiales de transporte y el humano. El consumo de vegetales crudos, ha sido asociado a numerosos casos de brotes de enfermedades por microorganismos patógenos como Listeria monocytogenes, Clostridium botulinum, Vibrio cholerae y Escherichia coli (3).

Las ETA son consideradas un problema de salud pública a escala mundial, siendo el agua y los alimentos las principales fuentes de enfermedades entéricas agudas. Se han descrito alrededor de 200 enfermedades de transmisión alimentaría, cuya etiología incluye bacterias, virus, hongos, parásitos, productos químicos y toxinas de origen vegetal. Se estima que anualmente se enferman unos 600 millones de personas ( 1 de cada 10 habitantes) por ingerir alimentos contaminados. Los niños menores de 5 años cerca de un 40\% contraen dicha enfermedad, que provocan cada año 125000 defunciones (2-5).

Ecuador es un país potencialmente agrícola con productos de primera necesidad que además son de exportación a nivel mundial (6). Es por ello, que se implementó un plan para mitigar la aparición de bacterias multiresistentes, proyecto presentado por La Organización de las Naciones Unidas para la Alimentación y la Agricultura (FAO) con el propósito de brindar asistencia técnica a los gobiernos para formular e implementar planes nacionales multisectoriales para controlar la resistencia antimicrobiana en la alimentación y la agricultura. Dentro de las principales fuentes de contaminación en la agricultura se encuentra el uso de agua de riego ya que ésta pudiera ser no potable, además, la ubicación geográfica de las huertas debido a que estas pudieran estar cerca de aguas residuales, proviniendo quizá de hospitales, casas, restaurantes, escuelas. En el agua de riego se encuentran bacterias patógenas, las cuales al poseer genes de virulencia y de resistencia a antibióticos pudieran transferir estos genes a bacterias no patógenas también presentes en estos ambientes (5).

Tomando en cuenta que los vegetales frescos forman parte esencial de la dieta humana y además pueden estar asociados con la transmisión de bacterias multiresistentes, el objetivo de esta investigación fue identificar los perfiles de resistencia antimicrobiana de bacterias aisladas en cultivos agrícolas de la cuenca del río Chambo.

\section{MATERIALES Y MÉTODOS}

Tipo de estudio: descriptivo con un diseño de campo y cohorte transversal.

Sitios de muestreo: se analizaron un total de 12 muestras de vegetales y hortalizas encontrados en las cercanías (500 m) de seis zonas agrícolas identificadas como puntos de recolección, cuyos productos son regados directamente del caudal del río Chambo, el cual cubre una superficie aproximada de $3.580 \mathrm{Km}^{2}$. El recorrido de este río atraviesa la provincia de Chimborazo que consta de cantones como: Penipe, Guamote, Alausí, Chambo, Colta, Riobamba y Guano. 
Donde se fijaron los seis puntos para la recolección de los diferentes cultivos agrícolas (figura 1).

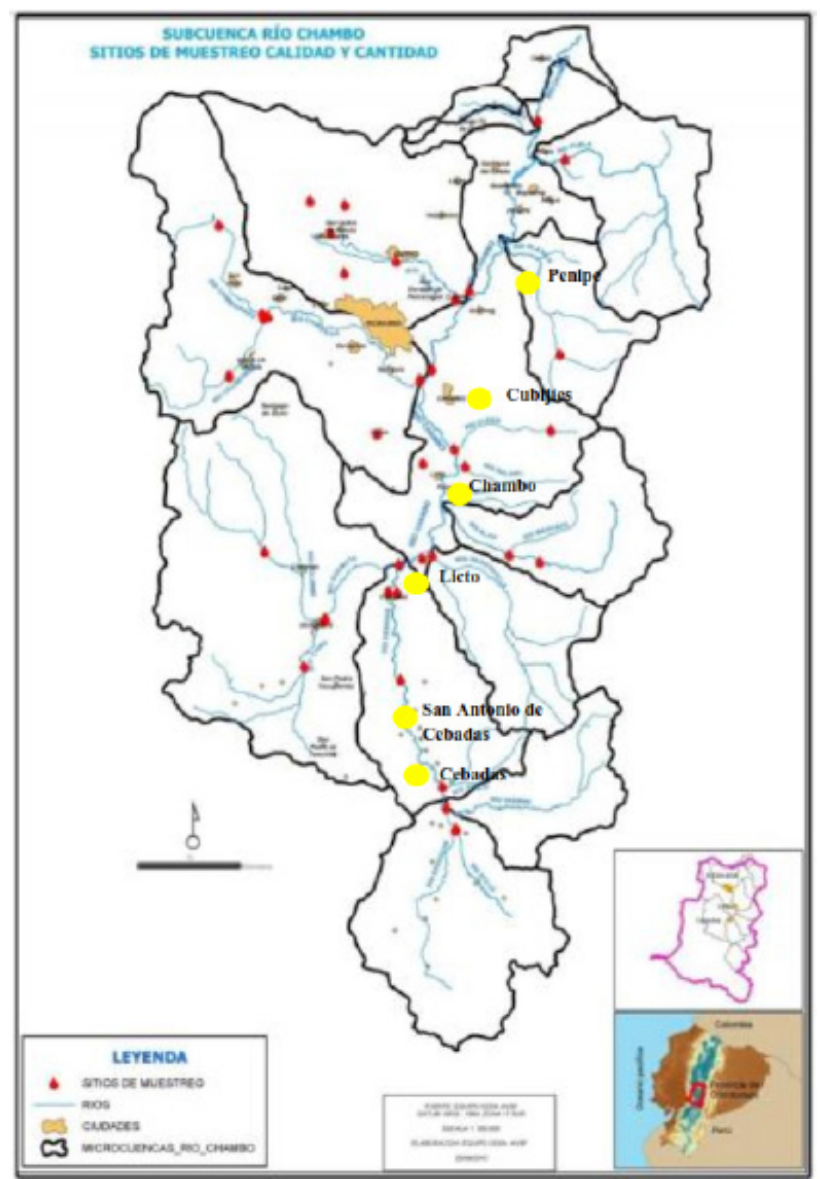

Figura1. Localización de las estaciones de muestreo a lo largo de la microcuenca del río Chambo.

Se tomó en cuenta la altitud y la variante climatológica temperatura de las zonas, este estudio se ejecutó durante el período abril - julio de 2019 (tabla 1).

\begin{tabular}{|l|l|l|l|l|}
\hline Puntos & $\begin{array}{l}\text { Estación de } \\
\text { muestreo }\end{array}$ & Ubicación & Altitud & $\begin{array}{l}\text { Temperatura } \\
\text { Ambiente }\left({ }^{\circ} \mathrm{C}\right)\end{array}$ \\
\hline Punto 1 & Chambo & $\begin{array}{l}\text { A } 100 \mathrm{~m} \text { de } \\
\text { la entrada a } \\
\text { Chambo }\end{array}$ & 2569 & 21 \\
\hline Punto 2 & $\begin{array}{l}\text { San An- } \\
\text { tonio de } \\
\text { Cebadas }\end{array}$ & $\begin{array}{l}\text { A 120 m Vía } \\
\text { Riobamba - } \\
\text { Macas }\end{array}$ & 2979 & 19 \\
\hline Punto 3 & Licto & $\begin{array}{l}\text { A 2 m de la En- } \\
\text { trada de Licto }\end{array}$ & 2730 & 20 \\
\hline Punto 4 & Cebadas & $\begin{array}{l}\text { A 200 metros } \\
\text { de la entrada a } \\
\text { Cebadas }\end{array}$ & 2907 & 20 \\
\hline Punto 5 & Penipe & $\begin{array}{l}\text { Entrada de } \\
\text { Penipe }\end{array}$ & 2361 & 19 \\
\hline Punto 6 & Cubijíes & $\begin{array}{l}\text { A 50 metros } \\
\text { de la entrada a } \\
\text { Cubijies }\end{array}$ & 2479 & 19 \\
\hline
\end{tabular}

Tabla 1. Datos de altitud y temperatura obtenidos en cada estación durante la recolección de productos agrícolas cercanos del río Chambo.
Muestras: las 12 muestras de vegetales y hortalizas se tomaron por duplicado de manera aséptica en bolsas estériles, posteriormente se selló, se asignó su respectiva codificación a cada bolsa y se conservó en refrigeración en una cava con hielo hasta el momento de su llegada al laboratorio de Microbiología, Facultad de Ciencias de la Salud, en la Universidad Nacional de Chimborazo, establecimiento donde se llevó a cabo análisis microbiológico.

Cultivo y aislamiento de cepas bacterianas presentes en los vegetales y hortalizas: Una vez que las muestras de productos vegetales fueron transportadas al laboratorio de Microbiología, se realizó el análisis microbiológico. Del centro del fruto del producto agrícola se tomó $25 \mathrm{~g}$ (triturado) y se colocó en $225 \mathrm{ml}$ de agua peptonada para realizar el pre- enriquecimiento y luego se incubaron por 24 horas a $37^{\circ} \mathrm{C}$. Posteriormente se tomó $1 \mathrm{ml}$ de cultivo y se inoculó en un tubo con $9 \mathrm{ml}$ de agua peptonada los cuales se incubaron 24 horas a $37^{\circ} \mathrm{C}$. Transcurrido el periodo de incubación se tomaron 10 microlitos del cultivo para sembrar por la técnica de agotamiento en los medios de cultivo agar MacConkey (MK) Acumedia $\odot$, Agar Sangre (AS) Himedia $\odot$, Cistina Electrolito Deficiente (CLED) DifcoTM y Tiosulfato Citrato Bilis Sacarosa (TCBS) DifcoTM.

Preparación de medios de cultivo: los medios de cultivo fueron preparados según instrucciones del fabricante. Todos los medios fueron autoclavados a 15 psi a $121^{\circ} \mathrm{C}$ durante 25 minutos, se enfrió y secolocó en cajas monopetry Greiner@ estériles, con un volumen aproximado de $15 \mathrm{~mL}$ sobreuna superficie horizontal y en tubos anteriormente esterilizados un volumen de $5 \mathrm{ml}$ respectivamente. Posteriormente solidificado el medio de cultivo se procedió almacenar en fundas de estériles para evitar la posible contaminación a una temperatura de $2-8^{\circ} \mathrm{C}$.

Técnica de aislamiento de colonias: la técnica empleada fue la siembra por agotamiento en agar. una vez obtenidas las colonias seguidamente se realizó la tinción de Gram y pruebas bioquímicas para la identificación bacteriana a través de métodos microbiológicas convencionales de acuerdo con los esquemas de Koneman et al (6). 
Pruebas bioquímicas para la identificación de bacterias: las pruebas bioquímicas utilizadas para las bacterias Gram positivas fueron la observación de $\alpha, \beta$, o $\gamma$ hemólisis en agar sangre, y las pruebas de catalasa, agar bilis esculina $\mathrm{y}$ crecimiento en caldo $\mathrm{BHI}$ con $\mathrm{NaCl}$ al 6,5\%.(6).

En el caso de las bacterias Gram negativas se realizaron las pruebas: oxidasa, agar kliger, agar urea, citrato, caldo malonato, agar motilidad-indol-ornitina (MIO) y agar lisina hierro agar (LIA) (6). El agar Kligler se utilizó para observar la fermentación de la glucosa o la lactosa, la presencia de $\mathrm{H}_{2} \mathrm{~S}$ y si había producción de gas o no. Se utilizó la urea para ver la producción de ureasa, el agar citrato como fuente de carbono y nitrógeno. El caldo Malonato se utilizó para diferenciar microorganismos entéricos según su capacidad de utilizar el manitol. Para observar la motilidad bacteriana, la producción de indol y la actividad enzimática ornitina descarboxilasa se usó el medio MIO y para detectar la desaminación o descarboxilación de la lisina se probó el medio LIA.

Determinación del perfil de susceptibilidad a los antibióticos de las cepas bacterianas aisladas e identificadas: a las bacterias aisladas, se les realizó ensayos de sensibilidad por el método de difusión del disco en agar Mueller Hinton (Oxoid Basingstoke, UK) de acuerdo a las instrucciones del Clinical and Laboratory Standard Institute (CLSI, 2019) (7).

Para realizar la prueba se transfirió una o dos colonias del cultivo a un tubo con solución fisiológica estéril, el crecimiento bacteriano se ajustó a la turbidez del patrón 0.5 del estándar de McFarland. Se introdujo un hisopo de algodón estéril dentro del tubo que contenía el inóculo estandarizado. Con el hisopo humedecido, se inoculó en tres o cuatro direcciones toda la superficie de una placa con agar Mueller Hinton. Se dejó secar el inóculo a temperatura ambiente durante $5 \mathrm{mi}$ nutos. Posteriormente se procedió a la colocación de los discos de antibióticos con una pinza estéril luego se incubaron las placas 24 horas a $37^{\circ} \mathrm{C}$. Transcurrido el periodo de incubación se realizó la lectura midiendo con una regla milimetrada, la zona clara alrededor del disco de antibiótico, el cual se corresponde con la inhibición del crecimiento bacteriano. Estos datos se compararon con los diámetros de zona establecidos para cada antibiótico en las tablas de interpretación internacional del CLSI 2019. La interpretación de los halos de inhibición permitieron expresar los resultados como sensible o resistente.

Se ensayaron los siguientes antimicrobianos (BD BBLTM, USA): ceftazidima (CAZ) $30 \mu \mathrm{g}$, Ceftriaxona (CRO) $30 \mu \mathrm{g}$, trimetoprim-sulfa (SXT) $\mathrm{x} \mu \mathrm{g}$, penicilina (P) $10 \mathrm{U}$, imipenem (IMI) $10 \mu \mathrm{g}$, tetraciclina (TE) $30 \mu \mathrm{g}$, ciprofloxacina (CIP) 5 $\mu \mathrm{g}$, gentamicina $(\mathrm{GM}) 10 \mu \mathrm{g}$, Amikacina $(\mathrm{AK})$ $30 \mu \mathrm{g}$, vancomicina (Va) $10 \mu \mathrm{g}$.

Para estos ensayos se utilizó como cepa control $P$. aeruginosa ATCC 25923, S. aureus ATCC 25923, K. pneumoniae ATCC 700603.

\section{Análisis Estadístico de Datos}

De los resultados obtenidos se procedió a la realización de tablas descriptivas con referencia a la frecuencia y porcentaje, aplicando hojas de cálculo pertenecientes al sistema operativo Microsoft Office 2013.

\section{RESULTADOS}

Se seleccionaron puntos estratégicos tomando como referencia la longitud del río y las zonas agrícolas de los distintos sectores para la recolección de productos cercanos al río Chambo. Los puntos fueron: Chambo, San Antonio de Cebadas, Licto, Cebadas, Penipe y Cubijíes (tabla 2).

\begin{tabular}{|l|l|l|}
\hline Puntos & Estación de muestreo & Producto agrícola \\
\hline Punto 1 & Chambo & Remolacha \\
\hline Punto 2 & San Antonio de Cebadas & Lechuga \\
\hline Punto 3 & Licto & Zanahoria \\
\hline Punto 4 & Cebadas & Frutilla \\
\hline Punto 5 & Penipe & Papas \\
\hline Punto 6 & Cubijíes & Ocas \\
\hline
\end{tabular}

Tabla 2. Estaciones de muestreo y productos agricolas recolectados.

Se aislaron e identificaron de los productos agrícolas procesados un total de 14 bacterias; 12/14 $(85,71 \%)$ pertenecientes a la familia Enterobacteriacea y $2 / 14(14,28 \%)$ a la familia Enterococcaceae. 
De la Remolacha se aislaron 2 cepas de Enterobacter cloacae y 1 de Enterococcus faecalis. De la lechuga se aisló 1 cepa de Citobacter amalonaticus y 1 de Proteus vulgaris. De las zanahorias, 2 cepas de Citrobacter freundii. De la frutilla, 1 cepa de E. faecalis y 1 de P. vulgaris. De las papas, 2 cepas de $C$. freundii y de las ocas, 2 cepas de Klebsiella oxytoca y 1 de E. cloacae (tabla 3).

El 50\% (6/12) de las enterobacterias aisladas de estos productos agrícolas presentaron resistencia a cefalosporinas de 3ra generación (ceftriaxona y ceftazidima), $50 \%(6 / 12)$ a kanamicina y $25 \%$ (3/12) a imipenem, gentamicina y trimetoprim sulfametoxazol (tabla 3 ).

Con respecto a la multirresistencia de las cepas de Enterobacterias estudiadas, el 16,7 \% (2/12) resultaron resistentes a seis antibióticos, 8,3\% (1/12) a cuatro antibióticos, $8,3 \%(1 / 12)$ a tres antibióticos y el 41,7 \% (5/12) a dos antibióticos (tabla 3).

\begin{tabular}{|c|c|c|c|c|c|c|c|c|c|c|c|c|c|c|}
\hline Estación de muestreo & Producto agrícola & Bacterias aisladas & $\mathrm{N}^{\circ}$ cepas bacterianas & $\begin{array}{l}\mathrm{C} \\
\mathrm{R} \\
\mathrm{O}\end{array}$ & $\begin{array}{l}\text { C } \\
\text { A } \\
\text { Z }\end{array}$ & $\begin{array}{l}\text { I } \\
\text { M } \\
\text { P }\end{array}$ & $\begin{array}{l}\mathbf{F} \\
\mathbf{O} \\
\mathbf{X}\end{array}$ & $\begin{array}{l}S \\
X \\
T\end{array}$ & $\begin{array}{l}\mathrm{C} \\
\mathrm{N}\end{array}$ & K & $\begin{array}{l}\mathrm{T} \\
\mathrm{E}\end{array}$ & $\begin{array}{l}\text { C } \\
\text { I } \\
\text { P }\end{array}$ & $\mathbf{P}$ & $\begin{array}{l}\text { V } \\
\text { A }\end{array}$ \\
\hline \multirow[t]{3}{*}{ Chambo } & \multirow[t]{3}{*}{ Remolacha } & E. cloacae (1.1) & 1 & $\mathrm{R}$ & $\mathrm{R}$ & $\mathrm{R}$ & $\mathrm{R}$ & $S$ & $\mathrm{R}$ & $\mathrm{R}$ & S & S & - & - \\
\hline & & E. cloacae (1.2) & 1 & $S$ & $S$ & S & $S$ & $S$ & $S$ & $\mathrm{R}$ & $\mathrm{R}$ & S & - & - \\
\hline & & E. faecalis (1.3) & 1 & - & - & - & - & - & - & - & S & S & $\mathrm{R}$ & $\mathrm{R}$ \\
\hline \multirow[t]{2}{*}{ San Antonio de Cebadas } & \multirow[t]{2}{*}{ Lechuga } & C. amalonaticus (2.1) & 1 & S & S & S & S & S & $\mathrm{R}$ & $\mathrm{R}$ & S & S & - & - \\
\hline & & P. vulgaris (2.2) & 1 & $\mathrm{R}$ & $\mathrm{R}$ & $\mathrm{R}$ & $\mathrm{R}$ & S & $\mathrm{R}$ & $\mathrm{R}$ & S & S & - & - \\
\hline \multirow[t]{2}{*}{ Licto } & \multirow[t]{2}{*}{ Zanahoria } & C. freundii (3.1) & 1 & $S$ & $\mathrm{R}$ & $\mathrm{R}$ & $\mathrm{R}$ & $\mathrm{R}$ & $S$ & $S$ & $S$ & $S$ & - & - \\
\hline & & C. freundii (3.2) & 1 & $\mathrm{R}$ & $\mathrm{R}$ & $S$ & S & $\mathrm{R}$ & S & $S$ & $S$ & $S$ & - & - \\
\hline \multirow[t]{2}{*}{ Cebadas } & \multirow[t]{2}{*}{ Frutilla } & E. faecalis $(4.1)$ & 1 & - & - & - & - & - & - & - & $S$ & $S$ & S & S \\
\hline & & P. vulgaris (4.2) & 1 & $\mathrm{R}$ & $S$ & $S$ & $S$ & $S$ & $S$ & $\mathrm{R}$ & $S$ & $S$ & - & - \\
\hline \multirow[t]{2}{*}{ Penipe } & \multirow[t]{2}{*}{ Papas } & C. freundii (5.1) & 1 & $S$ & $\mathrm{R}$ & $S$ & $S$ & $\mathrm{R}$ & S & $S$ & S & $S$ & - & - \\
\hline & & C. freundii (5.2) & 1 & $\mathrm{R}$ & $\mathrm{R}$ & $S$ & $S$ & $S$ & $S$ & $S$ & S & $S$ & S & $S$ \\
\hline \multirow[t]{3}{*}{ Cubijíes } & \multirow[t]{3}{*}{ Ocas } & K. oxytoca (6.1) & 1 & $S$ & $S$ & S & $S$ & S & $S$ & $\mathrm{R}$ & S & S & $S$ & $S$ \\
\hline & & K. oxytoca $(6.2)$ & 1 & $\mathrm{R}$ & S & $S$ & $S$ & S & $S$ & $S$ & $\mathrm{~S}$ & S & S & $S$ \\
\hline & & E cloacae (6.3) & 1 & - & - & - & - & - & - & - & S & S & $\mathrm{R}$ & $\mathrm{R}$ \\
\hline
\end{tabular}

Tabla 3. Perfiles de susceptibilidad a los antibióticos de cepas bacterianas aisladas de los productos agrícolas de la Cuenca del río Chambo. CRO: ceftriaxone; CAZ: ceftazidime; IMP: imipenem; FOX: cefoxitin; SXT: sulfa trimetropin, CN: gentamicina; K: kanamicina; TE: tetraciclina; CIP: ciprofloxacina; P: penicilina VA: vancomicina

Tres cepas expresaron fenotipos correspondientes a la producción de betalactamasas AmpC inducibles. Este mecanismo AmpC tipo cromosómico inducible, se pudo evidenciar fenotípicamente utilizando como agente inductor al imipenem y como sustrato a ceftazidima observándose un achatamiento en forma de $\mathrm{D}$ en el halo de inhibición de ceftazidima (figura 2).
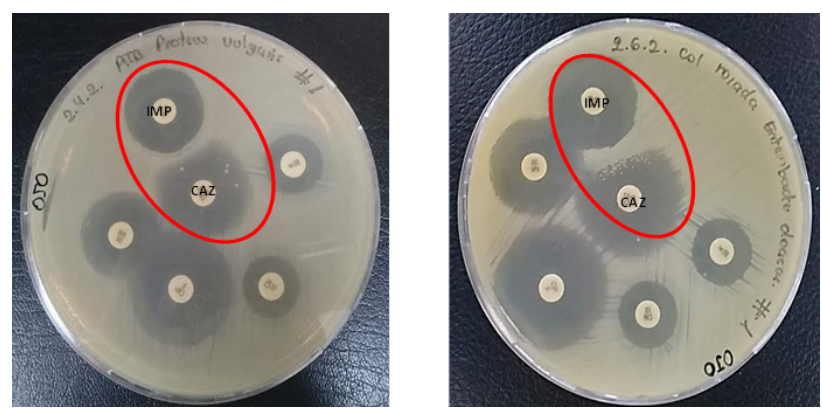

Figura 2. AmpC inducible en cepa de P. vulgaris y E. cloacae aislada de productos agrícolas.

\section{DISCUSIÓN}

Los alimentos vegetales son una de las principales vías de transmisión de microorganismos a través de la cadena alimentaria. En la superficie de las plantas en crecimiento existe una microbiota típica, que se puede contaminar por el aporte de microorganismos de distinta procedencia, como puede ser el origen animal que aporta al suelo y al agua, sus excretas (2).

Otra vía de contaminación son las aguas residuales y de riego, ya que los cultivos pueden ser regados por estas aguas sin tratar, existe la posibilidad de que los alimentos vegetales recién cosechados estén contaminados por microorganismos patógenos para el hombre, sobre todo por aquellos que producen trastornos gastrointestinales (8). 
La subcuenca del Río Chambo se encuentra ubicada en el centro del Ecuador, teniendo una superficie de $3580 \mathrm{~km}^{2}$ y cubre un 54\% de la superficie total de la provincia de Chimborazo, en esta zona se encuentra parte de los siete cantones de la provincia: Alausí, Riobamba, Chambo, Penipe, Guano, Colta y Guamote, donde se encuentran unos 33 ríos de tamaño variable según su ubicación geográfica y época del año. La subcuenca pertenece a la provincia en un $98 \%$ abarcando los humedales y zonas naturales, como los páramos (9).

En esta subcuenca se han desarrollado algunos estudios para conocer la calidad del agua en toda su extensión. El equipo técnico de la Central Ecuatoriana de Servicios Agrícolas-Agrónomos y Veterinarios Sin Fronteras (CESAAVSF) realizaron por primera vez estudios en 33 estaciones seleccionadas con dos muestres cada una. Como primeros indicadores de la calidad del agua se analizaron diversos parámetros tanto físicos, químicos y microbiológicos, evaluándose el oxígeno disuelto, $\mathrm{pH}$, temperatura, $\mathrm{PO}_{4}, \mathrm{NO}_{3}$, turbidez, conductividad, salinidad, solidos totales disueltos, presencia de coliformes totales y $E$. coli como principal indicador microbiológico de contaminación. Los resultados obtenidos de los distintos parámetros obtenidos confirmaron que los ríos Guano, Guate, Chibunga y Chambo se encuentran contaminados $(10,11)$.

En esta subcuenca donde se ubican los sitios agrícolas de muestreo no han sido desarrollados ningún estudio para evaluar los productos cosechados. Sin embargo, se ha reportado un trabajo similar donde se identificaron bacterias de interés clínico como: $C$. diversus, $C$. amalonaticus, $E$. aerogenes, E. cloacae, Hafnia alvei, Aeromona spp y Enterococcus spp aisladas de productos agrícolas regados con aguas del río Guano, Chimborazo, Ecuador (12).

En las zonas agrícolas seleccionadas (Chambo, San Antonio de Cebadas, Licto, Cebadas, Penipe y Cubijíes) cercanas al río Chambo donde se recolectaron los productos se siembran vegetales y hortalizas que se expenden a los mercados de Riobamba. Los agricultores de estas zonas implementan prácticas de producción orgánica. Los pequeños productores de estas zonas hacen un manejo racional de los recursos naturales, sin la utilización de productos de síntesis química para la obtención de alimentos sanos. Se ha descrito que en diversos puntos del río Chambo existe la presencia de coliformes fecales y E. coli como bacteria indicadoras de contaminación fecal, esto debido tanto a actividades humanas y ganaderas que se encuentren próximas al río, los productos agrícolas de estos sectores son regados con estas aguas contaminadas de donde se asume que llegan las bacterias multiresistentes (13).

Las bacterias más prevalentes descritas tanto en estudios realizados en el agua como en los productos agrícolas regados con las aguas de los ríos Chambo y Guano son enterobacterias y E. faecalis $(11,12)$.

En el presente estudio, se encontró que el 83,3\% de las bacterias aisladas de los productos agrícolas obtenidos de los puntos cercanos al río Chambo correspondían a enterobacterias de los siguientes géneros: Citrobacter, Enterobacter, Klebsiella y Proteus bacterias comúnmente encontradas en agua, suelos, vegetación y microbiota intestinal de animales (14). Considerados potenciales bioindicadores de calidad del agua con bajo potencial patógeno y corresponden a $10 \%$ de los microorganismos intestinales humanos y animales, por lo que su presencia en el agua está asociada con contaminación fecal e indica tratamientos inadecuados o contaminación posterior (15).

Por otro lado, en los productos como las remolachas y ocas se aisló cepas de E. faecalis la presencia de esta bacteria es considerado como un indicador de contaminación fecal de fuentes humanas (16). También está involucrada en el deterioro de los alimentos, en intoxicaciones alimentarias y en la propagación de resistencia a los antibióticos a través de la cadena alimentaria (17).

La presencia de Enterococcus spp. en ambientes tales como el agua, alimentos y el aire pudiesen estar relacionados a su transmisión, en especial con diseminación tanto de patrones de resistencia a antibióticos como en la producción de enfermedades (17). 
El uso de antibióticos en diversas áreas incluyendo la agrícola ha aumentado lo cual pudiera facilitar la adquisición de resistencia a los mismos por parte de bacterias presentes en dicho ambiente, sean patógenas o no. Dicha adquisición de resistencia pudiera realizarse a través de la transferencia horizontal de elementos genéticos móviles tales como transposones, plásmidos o integrones $(18,19)$.

El uso inadecuado de antibióticos en medicina humana, veterinaria y agrícola propicia la liberación de estos antibióticos al medio ambiente. Junto con estos antibióticos, bacterias con resistencia a ellos se pudieran liberar en las aguas que pudieran irrigar diversos cultivos (20).

Se cree que las plantas de tratamiento de aguas residuales son probables puntos críticos para la diseminación de la resistencia a los antibióticos en el medio ambiente, ya que ofrecen condiciones convenientes para la proliferación de resistencia bacteriana, así como para la transferencia horizontal de genes de resistencia entre diferentes microorganismos. De hecho, genes que confieren resistencia a todas las clases de antibióticos junto con elementos genéticos móviles como plásmidos, transposones, bacteriófagos, integrones se detectan en bacterias aisladas de las plantas de tratamiento de aguas residuales de diferentes países. Parece que estas plantas con procesos de tratamiento convencionales son capaces de reducir significativamente la resistencia bacteriana a los antibióticos pero no son eficientes en la eliminación de genes de resistencia. La implementación de procesos avanzados de limpieza de aguas residuales además de un tratamiento de aguas residuales convencional es un paso importante para proteger el medio ambiente acuático (20).

Estudios previos con respecto a la incidencia de bacterias con resistencia a antibióticos provenientes de agua de riego y productos agrícolas incluyen la búsqueda de resistencia a antibióticos en diferentes especies de Enterobacteriales y Enterococcus. En un estudio llevado a cabo por Abriouel et al., (21) donde analizaron diferentes cepas de enterobacterias y Enterococcus spp. provenientes de frutas, vegetales, agua y suelo reportaron resistencia a antibióticos como quinupristina/dalfopristina, estreptomicina, nitrofurantoína, levofloxacina, ciprofloxacina, rifampicina, cloranfenicol, tetraciclina, eritromicina y penicilina. En otro estudio realizado por Odonkor y Addo, (22) buscaron la prevalencia de resistencia a antibióticos en cepas de E. coli provenientes de fuentes de agua de riego, en las cuales, encontraron que $32.99 \%$ presentaba resistencia a penicilina, así como cefuroxima $(28.87 \%)$, eritromicina (23.71\%), tetraciclina $(21.45 \%)$, ampicilina (11.32\%) y ciprofloxacina (8.25\%).

En el presente estudio, las Enterobacterias aisladas de los productos agrícolas presentaron resistencia a ceftriaxona (50\%), ceftazidima (50\%), kanamicina (50\%), imipenem (25\%), gentamicina $(25 \%)$ y trimetoprim sulfametoxazol (25\%). Es importante destacar que tres cepas de E. cloacae (cepa 1.1), C. freundii (cepa 1.1) y P. vulgaris (cepa 2.2) expresaron fenotipos correspondientes a la producción de betalactamasas AmpC inducibles.

Las bacterias de los géneros Enterobacter y Citrobacter poseen de manera natural estas betalactamasas lo que explica su resistencia natural a las aminopenicilinas, cefalosporinas de 1ra generación, cefamicinas (cefoxitina, cefotetán) y aminopenicilinas combinadas con inhibidores de betalactamasas (amoxicilina-ácido clavulánico, ampicilina-sulbactam).

La cepa de $P$. vulgaris presentó fenotipo de resistencia presuntivo a betalactamasa tipo AmpC plasmidica inducible lo cual tendría que ser comprobado por métodos moleculares. Los genes ampC mediados por plásmidos han sido encontrados en bacterias como Salmonella spp., $K$. pneumoniae y $P$. mirabilis que naturalmente no poseen estos genes (23). La evidencia molecular sugiere que los genes que codifican a estas enzimas, derivan de los genes ampC cromosómicos que naturalmente poseen las enterobacterias de los géneros Enterobacter spp., Providencia spp., Morganella morganii, Serratia marcescens, C. freundii y $H$. alvei Estos genes han sido integrados en elementos genéticos transferibles facilitando la diseminación a diferentes bacterias (24).

En relación a las 2 cepas de E. faecalis aisladas, 
presentaron resistencia a penicilina y vancomicina. La resistencia de Enterococcus spp. a diversos agentes antimicrobianos supone un problema de salud pública que afecta a todo el mundo, sobre todo a los países en los que el uso de antibióticos no está especialmente regulado (25).

La resistencia adquirida de Enterococcus a múltiples antibióticos se ve favorecida por la acumulación de mutaciones y resistencias adicionales adquiridas a través de genes exógenos (16). El genoma de estas bacterias se caracteriza por poseer la capacidad de incorporar a través de elementos genéticos móviles exógenos, genes de resistencia a multitud de antibióticos, así como de transferir determinantes de resistencia generados por ellos mismos tras la exposición a ciertos antibióticos a otras especies patógenas $(25,26)$.

La presencia de Enterococcus spp. en los alimentos también puede suponer una amenaza debido al impacto negativo que puede causar la dispersión de la resistencia a antibióticos a través de la cadena alimentaria. En alimentación animal se utilizan multitud de agentes antimicrobianos como terapia y profilaxis frente a infecciones bacterianas y para fomentar el crecimiento animal. Este uso excesivo de antibióticos en producción animal se relaciona directamente con el aumento de las resistencias a los antibióticos, encontrando similitudes entre las cepas de Enterococcus spp. de origen animal con cepas de Enterococcus spp. proveniente de infecciones humanas nosocomiales (27). Enterococcus spp., exhibe una variedad de mecanismos de resistencias intrínsecas y adquiridas frente a las mayores clases de antibióticos de uso clínico y están dota- dos de mecanismos de intercambio genético eficientes que facilitan la diseminación de los genes de resistencia a antibióticos (28). Las resistencias adquiridas especialmente frente a penicilina/ampicilina, aminoglicósidos y glicopéptidos han ido en aumento, limitando su espectro terapéutico.

Existen evidencias científicas que relacionan el uso de antibióticos en la cría de animales con la aparición de cepas de Enterococcus spp., resistentes en los alimentos, corroborando la implicación de éstos en la diseminación de resistencias con repercusión en Salud Pública (29-30).

\section{CONCLUSIONES}

Los resultados de este estudio reflejan que existe contaminación de los cultivos agrícolas vertidos con agua de regadío de la cuenca del río Chambo por especies de enterobacterias y E. faecalis; con altos porcentajes de resistencia a antibióticos de uso clínico betalactamicos, aminoglucósidos y trimetoprim sulfa, además tres cepas de enterobacterias expresaron fenotipos de resistencia correspondientes a la producción de betalactamasas AmpC inducibles y 2 cepas de E. faecalis presentaron resistencia a vancomicina y penicilina, de allí la necesidad de considerar establecer criterios que requieren el esfuerzo conjunto de gobiernos, productores y consumidores, implementando procesos de tratamiento de aguas residuales eficientes, así como realizar un seguimiento microbiológico permanente teniendo en cuenta el aspecto de la resistencia a los antibióticos, junto con un mayor control de la ingesta de medicamentos y una adecuada gestión de los residuos médicos.

$\mathrm{R}$ eferencias

1. Rivera-Jacinto M, Rodríguez-ulloa C, López-Orbegoso J. Contaminación fecal en hortalizas que se expenden en mercados de la ciudad de Cajamarca, Perú Rev Peru Med Exp Salud Publica.[Internet]. 2009 [citado 2021 Jun 30] ; 26(1): 45-48. Disponible en: http://www.scielo.org. pe/scielo.php?script=sci_arttext\&pid=S1726-46342009000100009\&lng=es.

2. Alegbeleye, Oluwadara Oluwaseun, Ian Singleton, y Anderson S. Sant'Ana. 2018. Sources and contamination routes of microbial pathogens to fresh produce during field cultivation: A review. Food Microbiol. [Internet]. 2018 [citado 2021 Jun 30]; 73 : 177-208. Disponible en: https:// pubmed.ncbi.nlm.nih.gov/29526204/.

3. Rodríguez Torrens H, Barreto Argilagos G, Sedrés Cabrera M, Bertot Valdés J, Martínez Sáez S, Guevara Viera G. Las enfermedades transmitidas por alimentos, un problema sanitario que hereda e incrementa el nuevo milenio REDVET. [Internet]. 2016 [citado 2021 Jun 30]; 16 (8): 
1-27. Disponible en: http://www.redalyc.org/articulo.oa?id=63641401002.

4. Zúñiga Carrasco IR, Caro Lozano J. Enfermedades transmitidas por los alimentos: una mirada puntual para el personal de salud. [Internet]. 2017 [citado 2021 Ago 20]; 37 (3): 95-104. Disponible en: chrome-extension://efaidnbmnnnibpcajpcglclefindmkaj/viewer.html?pdfurl=https\%3A\%2F\%2Fwww.medigraphic.com\%2Fpdfs\%2Fmicro\%2Fei-2017\%2Fei173e.pdf\&clen $=161529 \&$ chunk $=$ true

5. Castro Delgado ZL. Presencia de microorganismos patógenos y genes de virulencia y resistencia a antibióticos en agua de riego en huertas de Chihuahua, Puebla y Veracruz. 2020. Universidad Autónoma de Nuevo León. Facultad de Ciencias Biológicas. Disponible en: http://eprints. uanl.mx/id/eprint/20892.

6. Koneman EW, Winn WC. Enterobacteriaceae. En: Koneman Diagnóstico Microbiológico: Texto y Atlas en color. 6ta. edición. Buenos Aires: Editorial Médica Panamericana; 2008. p. 205-62.

7. Clinical and Laboratory Standards Institute (CLSI). Performance standards for antimicrobial susceptibility testing Clinical and Laboratory Standards Institute Wayne, PA. 2019.

8. Antwi-Agyei P, Cairncross S, Peasey A, Price V, Bruce J, Baker K, et al. A Farm to Fork Risk Assessment for the Use of Wastewater in Agriculture in Accra, Ghana. PLOS ONE. [Internet]. 2015 [citado 2021 Ago 20]; 10 (11):1-19. Disponible en: https://doi.org/10.1371/journal. pone. 0142346.

9. Aportes a la planificación para la gestión integral de los recursos hídricos: Contribución del Comité de la Subcuenca del río Chambo [Internet]. 2015 [citado 22 de noviembre de 2021]; p 30. Disponible en: http://cesa.org.ec/wpcontent/uploads/2018/07/aportes-a-la-planificacic3b3n-para-la-girrhhpresentado-3.pdf

10. Subcuencachambo.wordpress.com. [Internet]. Ecuador: 2015 [actualizado 6 de abril de 2015; citado 22 de noviembre de 2021]. Disponible en:https://subcuencachambo.wordpress.com/ diagnostico-de-la-subcuenca/

11. Molina J, Orozco J. Detección de resistencia antimicrobiana en bacterias de interés clínico aisladas en el Río Chambo. UNACH. [Internet]. 2019 [citado 22 noviembre de 2021]. Disponible en: http://dspace.unach.edu.ec/bitstream/51000/5557/1/UNACH-EC-FCS-LAB-CLIN-2019-0007. pdf

12. Cazares Silva M. Bacterias patógenas para el hombre aisladas en productos agrícolas provenientes de la cuenca del Rio Guano. UNACH. [Internet]. 2019 [citado 22 noviembre de 2021]. Disponible en: http://dspace.unach.edu.ec/handle/51000/6222

13. Bautista V. Estudio de la calidad del agua de la cuenca del Río Chambo en época de estiaje. [Internet]. 2014 [citado 10 febrero de 2018]. Disponible en: http://dspace.espoch.edu.ec/handle/123456789/3221

14. Ríos S, Agudelo R, Gutiérrez L. Patógenos e indicadores microbiológicos de calidad del agua para consumo humano. Rev. Fac. Nac. Salud Pública [Internet]. 2015 [citado 2021 Ago 20]; 35 (2): 236-47. Disponible en: http://www.scielo.org.co/pdf/rfnsp/v35n2/0120-386X-rfnsp-35-0200236.pdf

15. Robert-Pullés M. Microorganismos indicadores de la calidad del agua potable en Cuba. Revista CENIC. Ciencias Biológicas [ Internet] 2014 [citado 2021 Ago 26]; 45(1): 25-36. Disponible en: http://www.redalyc.org/ pdf/1812/181230079005.pdf.

16. Larrea Murrell J A, Rojas Badía M M, Romeu Alvarez B, Rojas-Hernández M, Heydrich-Pérez M. Bacterias indicadoras de contaminación fecal en la evaluación de la calidad de las aguas: revisión de la literatura. Rev CENIC Ciencias Biológicas [Internet]. 2013 [citado 2021 Ago 20]; 44 (3): 24-34. Disponible en: http://www.redalyc.org/articulo.oa?id=181229302004

17. Russo N, Caggia C, Pino A, Coque TM, Arioli S, Randazzo CL. Enterococcus spp. in Ragusano PDO and Pecorino Siciliano cheese types: A snapshot of their antibiotic resistance distribution. Food Chem Toxicol. [Internet]. 2018 [citado 2021 Ago 20]; 120: 277-286. Disponible en: 
https://pubmed.ncbi.nlm.nih.gov/30009890/

18. Pierre S, Passerat J. 2009. Antimicrobial resistance of fecal bacteria in waters of the Seine river watershed (France). Sci Total Environ. [Internet]. 2009 [citado 2021 Ago 20]; 408(2):365-72. Disponible en: https://pubmed.ncbi.nlm.nih.gov/19853889/

19. Silva J, Asserella L, Bolados N, Herrera N, Leyton J. Resistencia a antimicrobianos en cepas de Enterococcus spp. aisladas en hospitales del Norte de Chile. Revista Chilena Infectologia [Internet]. 2006 [citado 2021 Ago 20]; 23(3):226-231. Disponible en: http://www.scielo.cl/scielo.php?script=sci_arttext\&pid=S0716-10182006000300005\&lng=es.

20. Pazda M, Kumirska J, Stepnowski P, Mulkiewicz E. (2019). Antibiotic resistance genes identified in wastewater treatment plant systems - A review. Sci Total Environ. [Internet]. 2019 [citado 2021 Ago 22]; 697:134023. Disponible en: https://pubmed.ncbi.nlm.nih.gov/31479900/.

21. Abriouel H, Omar NB, López RL, Gálvez A. La doble faceta del género Enterococcus y su importancia en alimentos. Real Acad Ciencias Vet Andalucía Orient [Internet]. 2008 [citado 2021 Ago 22]; 21:66-74. Disponible en: https://dialnet.unirioja.es/servlet/articulo?codigo=3327057.

22. Odonkor ST, Addo KK. Prevalence of Multidrug-Resistant Escherichia coli Isolated from Drinking Water Sources. Int J Microbiol. [Internet]. 2018 [citado 2021 Ago 23]; 2018(7204013):1-7. Disponible en: https://pubmed.ncbi.nlm.nih.gov/30210545/.

23. Martínez Rojas DV. Betalactamasas tipo AmpC: Generalidades y métodos para detección fenotípica. Rev. Soc. Ven. Microbiol. [Internet]. 2009 [citado 2021 Ago 30]; 29(2):78-83. Disponible en: http://ve.scielo.org/scielo.php?script=sci_arttext\&pid=S1315-25562009000200003\&lng=es.

24. Philippon A, Arlet G, Jacoby G. Plasmid-determined AmpC-type $\beta$-lactamases. Antimicrob Agents Chemother. [Internet]. 2002 [citado 2021 Ago 30]; 46:1-11. Disponible en: https:// www.ncbi.nlm.nih.gov/pmc/articles/PMC126993/.

25. Gökmen M, Önen A, Ektik N, Kara R, Torlak E, Metli M. Detection of Prevalence, Antibiotic Resistance and Virulence Factors of Enterococcus spp. Isolated From Ready to Eat Foods . Kocatepe Vet J. [Internet]. 2017 [citado 2021 Ago 30]; 10(2):76-82. Disponible en: https://dergipark.org.tr/tr/pub/kvj/issue/32997/368499.

26. Rehaiem A, Fhoula I, Slim AF, Ben Boubaker I.B, Chihi AB, Ouzari H. Prevalence, acquired antibiotic resistance and bacteriocin production of Enterococcus spp. isolated from tunisian fermented food products. Food Control. [Internet]. 2016 [citado 2021 Ago 30]; 63: 259-266 Disponible en : 10.1016/j.foodcont.2015.11.034.

27. Marin A, Gálvez A y Pérez R. Antimicrobial Resistance in Enterococci. J Infect Dis Ther. [Internet]. 2014 [citado 2021 Ago 30]; 2: 150. Disponible en : https://www.readcube.com/articles /10.4172\%2F2332-0877.1000150.

28. McGowan L, Jackson C, Barrett J, Hiott L, Fedorka-Cray P. Prevalence and antimicrobial resistance of enterococci isolated from retail fruits, vegetables, and meats. J Food Prot [Internet]. 2006 [citado 2021 Ago 30]; 69 (12): 2076-82 Disponible en: https://pubmed.ncbi.nlm.nih. gov/17186667/

29. Hanchi H, Mottawea W, Sebei K y Hammami R. The Genus Enterococcus: Between Probiotic Potential and Safety Concerns-An Update. Front. Microbiol. [Internet]. 2018 [citado 2021 Ago 30]; 9: 1791 Disponible en: https://doi.org/10.3389/fmicb.2018.01791

30. Vandera E, Lianou A, Kakouri A, Feng J, Koukkou A, Samelis J. Enhanced control of Listeria monocytogenes by Enterococcus faecium KE82, a multiple enterocin-producing strain, in different milk environments. J. Food Protect. [Internet]. 2017 [citado 2021 Ago 30]; 80 (1): 74-85 Disponible en: https://pubmed.ncbi.nlm.nih.gov/28221890/ 